\title{
Mechanical Properties of the Vertical Joints of Prefabricated Underground Silo Steel Plate Concrete Wall
}

\author{
Jun Chuai, Zhilong Hou (D, Zhenqing Wang, and Lumin Wang \\ College of Civil Engineering and Architecture, Henan University of Technology, Zhengzhou, China \\ Correspondence should be addressed to Zhilong Hou; zhilonghou@stu.haut.edu.cn
}

Received 16 October 2020; Revised 6 November 2020; Accepted 28 November 2020; Published 21 December 2020

Academic Editor: Jiang Jin

Copyright (c) 2020 Jun Chuai et al. This is an open access article distributed under the Creative Commons Attribution License, which permits unrestricted use, distribution, and reproduction in any medium, provided the original work is properly cited.

\begin{abstract}
Reliable joint connection is key to designing prefabricated structures. To study the mechanical properties of the vertical joints in the designed prefabricated underground silo steel plate concrete composite wall and verify their reliability, flexural and compressive experiments were conducted using two groups of six full-scale steel plate concrete composite wall specimens; the mechanical properties between jointed and jointless specimens were compared and analyzed. The experimental results indicate that all specimens are in the elastic stage during the entire loading process; further, they exhibit large stiffness and high bearing capacity without damages. Thus, the designed vertical joints of the steel plate concrete composite wall provide a reliable connection that is safe and applicable. Further, the flexural and compressive properties of jointed and jointless specimens were found to be similar; the newly designed prefabricated underground silo steel plate concrete composite wall could be designed using the "equivalent principle" that the combined wall design calculation with the joint could be equivalent to that without the joint.
\end{abstract}

\section{Introduction}

Food security concerns national economy and people's livelihood as well as national strategic security. To ensure national food security, China has established a grain reserve system and implemented a grain reserve strategy [1]. Underground silos have advantages such as low-temperature grain storage, lower land consumption, energy conservation, and environmental protection, while providing privacy and safety. It is an important foundation for building green and ecological grain storage systems, thereby providing good environmental, economic, and social benefits $[2,3]$. In recent years, many researchers have studied large-diameter reinforced concrete underground silos [4-6], thereby laying a solid foundation for further research in this field. With social development and technological progress under the background of green ecology, energy saving, and environmental protection, to the best of the author's knowledge, this is the first study to propose and design a prefabricated steel plate concrete underground silo (hereinafter, prefabricated underground silo). Prefabrication and steel plate concrete composite structure technologies are adopted to solve key technological difficulties faced by current underground silos and to promote the research and application of underground silos.

In this paper, the prefabricated technology is based on reverse construction to ensure the connection between the prefabricated block of the silo wall and the foundation pit support, which shortens the wet operation construction period and reduces construction cost; this technology has been studied in the field of tunnel lining engineering. Currently, the experimental research methods of tunnel lining focus on the integral ring test [7-12] and joint test [13-20]. Compared to the joint test, the loading device of the integral ring test is more complex and less applicable, which can only be used for specific test object and test purpose [9-11]. In addition, the mechanical properties of the joints in the assembled structure are very important to evaluate the overall force performance of the structure. Zhang et al. [13] designed a set of flexural loading devices that can create segment joints under compression and bending stress; they performed a series of full-scale test studies on the joints 
under different axial forces and bending moments. Geng et al. [14] used numerical simulation to study the feasibility of the local test of the longitudinal joint formed between two segment rings, and they then carried out the local full-scale test of the longitudinal joint to study the force and deformation characteristics of the joint. Jin et al. [16] performed the ultimate flexural strength test of the segment joints of large cross-section rectangular shield tunnels; the mechanical properties and the entire process of the failure of segment joints were studied by analyzing the seam angle and joint deflection; Kazuyoshi et al. [19] studied the law of vertical deformation and rotational deformation in pipe segment joints with a bending moment based on the joint test. Moreover, Zhang et al. [20] performed a load test of shield tunnel segment joints, and they compared the bending joint and direct joint full-scale specimens, which indicated that the stress and deformation law of the bending joint is the same as that of the direct joint. It is appropriate to replace the toggle joint with a direct joint only from the angle of bending stiffness evaluation of the joints.

A composite structure comprising the steel plate and concrete has been widely used in the construction of longspan bridges and high-rise and super high-rise building structures because of its high bearing capacity, high rigidity and ductility, good seismic performance, constructability, and relatively low cost; it achieves good economic and social benefits [21-25]. Yu et al. [26] performed an experimental study on a high-strength concrete composite shear wall with four built-in steel plates, and they showed that a high content of steel in the wall can increase the bearing capacity of the test piece and limit the development of cracks in concrete. Liang et al. [27, 28] studied the local stability of the steel plate and the force mechanism of the steel plate after buckling when the steel plate-concrete composite structure was subjected to biaxial axial compression. Tian et al. [29] studied the design method of steel plate concrete shear wall shear studs, and they determined the maximum ratio of stud spacing to steel plate thickness. By means of experimental research and numerical analysis, $\mathrm{Wu}$ et al. [30] studied the shear capacity, deformation, and crack development of steel plate-concrete composite slab. Yang et al. [31] performed the flexural experiment of the steel plate-concrete composite slab, which showed that the specimen designed according to the complete shear connection showed a similar failure pattern with a balanced-reinforced beam, thereby exhibiting good flexural bearing capacity and ductility.

Assembly technology and composite structure technology are gaining popularity in the field of engineering. However, there are few reports on the application of the two methods in the underground storage, and the joint connection mode, structural form, mechanical characteristics, and other aspects of the tunnel segment are also considerably different. The joints designed in this paper adopt dry joint, and the prefabricated blocks are connected by steel plates in the form of welding seams. Thus, the residual stress in the welding process inevitably affects the strength of the joint $[32,33]$. It is urgent to test whether the joint connection mode of the steel plate concrete composite wall of the prefabricated underground granary is reliable. Its mechanical properties determine the selection of the structural calculation method, and therefore, this paper focuses on the flexural and compressive mechanical properties of the composite bin wall joints; compared with the control group, the bending and compressive stiffness of the steel plate concrete silo wall with the control group was analyzed, and the reliability and operability of the designed joint were verified. It is of great significance to provide an experimental basis for the structural design and engineering application for this type of prefabricated underground silo.

\section{Structural Scheme of Prefabricated Underground Silo}

The stated prefabricated underground silo is an underground thin-walled cylindrical structure composed of a top plate, a bottom plate, an inner silo, a composite wall, and a steel pile. Figure 1 shows a section diagram of the prefabricated underground silo. Its capacity is $5000 \mathrm{t}$ (in wheat), and it is buried below the surface with a covering soil depth of $\sim 1.5 \mathrm{~m}$; the inner diameter of the silo is $25 \mathrm{~m}$, the wall thickness is $0.31 \mathrm{~m}$, the elevation of the silo floor (funnel shape) is $-21 \mathrm{~m}$ to $-28 \mathrm{~m}$; the height of the composite wall is about $20 \mathrm{~m}$; and 36 steel piles are uniformly distributed around the silo. Further, there are equipment interlayers in the silo.

In the structural scheme, a steel plate concrete composite structure is used for the roof and floor of the silo, and a prefabricated reinforced concrete structure is used for the inner barrel and equipment interlayer. In the reverse construction, 36 steel piles (HW400X400X13X21) which were first driven around the foundation pit are not only supporting piles but also structural stressed piles. The composite wall is first assembled by 36 prefabricated steel plate concrete blocks to form the first section of cylinder; the plane layout of the prefabricated underground silo composite wall is shown in Figure 2. The soil is excavated from the top to the bottom. Each time a section of soil is excavated, a section of the cylinder is formed by assembling prefabricated blocks, and the entire silo is formed in turn from each section of the cylinder. The structural scheme can realize the integrated design and construction of the composite wall and foundation pit support, and reverse construction is adopted to avoid large excavation and solve the difficult problem of the foundation pit support; the dry joint between the steel pile and the prefabricated block of steel plate concrete wall is used to form a whole and shorten the construction period; the steel pile can be used as uplift pile to solve the problem of long construction periods in underground wetting operations and antifloating. The single-sided steel plate lining of composite structure is not only a structural layer, but also a waterproof layer. The scheme provides foundation pit support, antifloating, and waterproofing, and it also reduces construction cost.

This paper focuses on the composite wall and its joints. The composite wall is assembled using a prefabricated single-sided steel plate concrete prefabricated block. The 


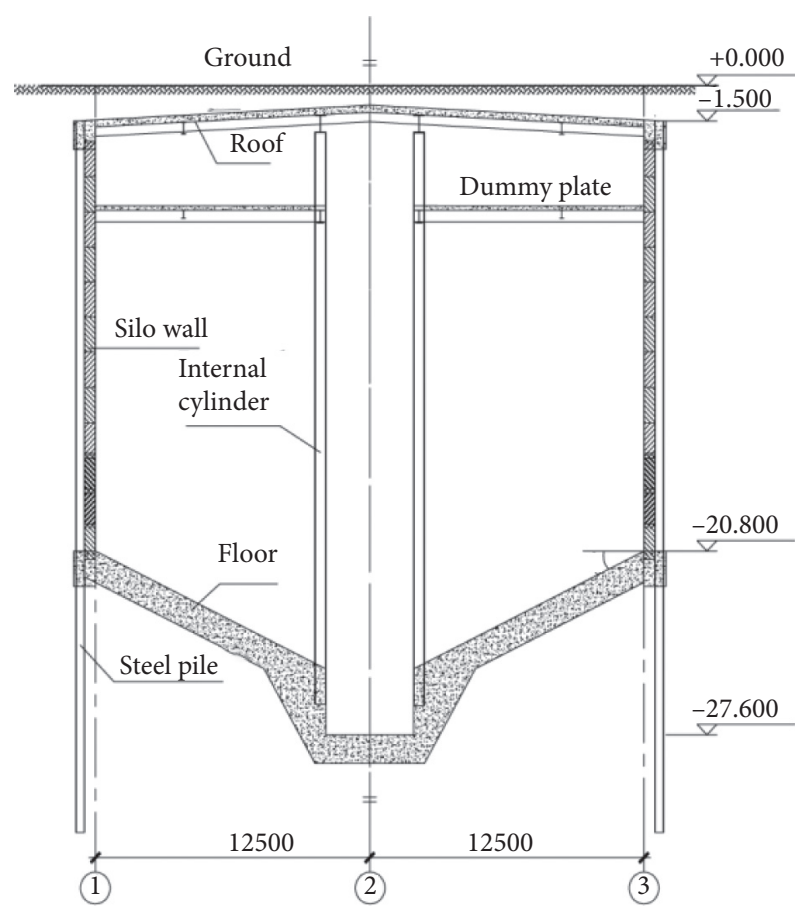

FIGURE 1: Section diagram of the prefabricated underground silo.

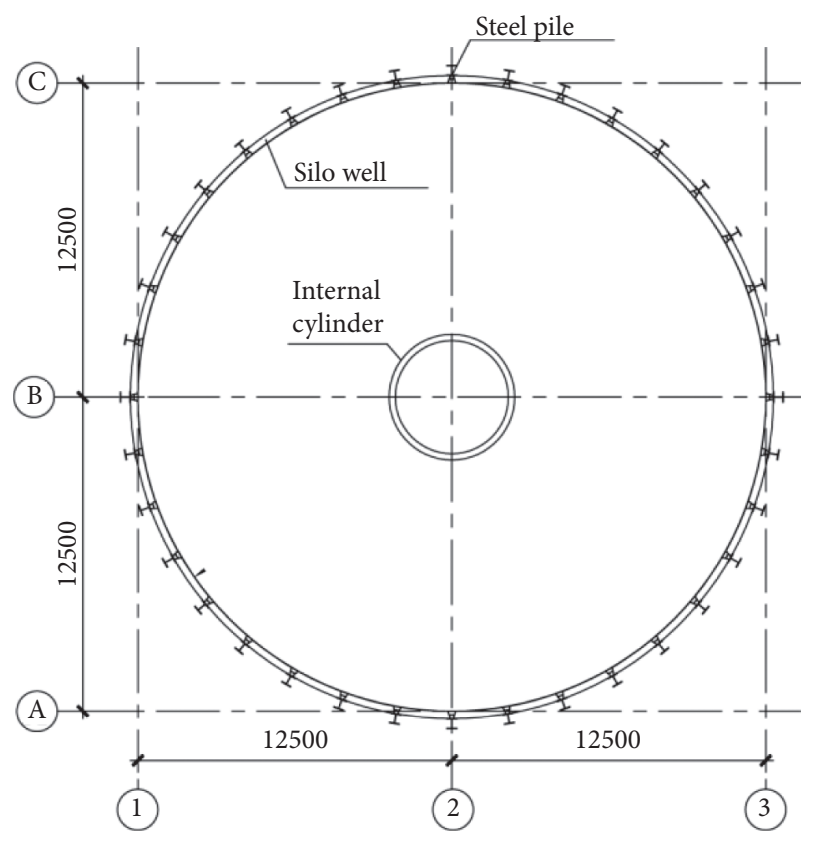

Figure 2: Plane layout of the prefabricated underground silo composite wall.

inner layer of the prefabricated block is a steel plate, and the outer layer is reinforced concrete. The two parts are connected together by cylindrical head bolts. The joint form between prefabricated blocks is as follows. Along the wall height between the left and right prefabricated blocks is a vertical joint, thereby applying a "horn-shaped" cavity joint (convenient for construction). Its components are two $U$ bound steel plates, sealing-up steel plate, load-transfer steel plate, the flange plate of the steel pile, which are joined together by welding the seam as one as shown in Figure 3. The warehouse silo wall is circumferentially jointed along the upper and lower prefabricated blocks, and the "mortise" docking method is adopted as shown in Figure 4.

\section{Experimental Objective}

The composite wall of the prefabricated underground silo is assembled using several steel plate concrete prefabricated blocks, and joints inevitably exist between the prefabricated blocks. If the stiffness, strength, and stability of the jointed composite walls are ensured such that they are not lower than those of jointless composite walls with the same thickness, the equivalent principle [6] can be used to design the composite walls. According to cylindrical shell theory, the circumferential stress of a composite wall under external pressure is considerably larger than axial stress, and its firstorder buckling mode is radial deformation along the cylinder (ellipse); therefore, this paper studies the mechanical properties of its vertical joint.

The following experiment objectives are considered in this study: (1) to verify that the flexural stiffness of jointed specimens is not lower than that of jointless specimens; (2) to verify that the strength of jointed specimens can meet the engineering design requirements; (3) to verify the validity of the established finite element calculation model; (4) to verify the reliability of the designed joints and the feasibility of their processing, fabrication, and construction technology.

\section{Design and Fabrication of Specimens}

4.1. Design Principles and Methods of Specimens. The design principle in this study is that the stiffness, strength, and stability of jointed composite walls are not less than those of jointless composite walls with the same wall thickness. Theoretical calculation and the finite element method are applied to design the specimens. When the structure form and force are determined, its stability depends on flexural rigidity. Previously, the numerical simulation analysis of steel plate concrete composite wall of prefabricated underground silo under the most unfavorable conditions (empty silo) was carried out. It was found that, when the ratio of the flexural stiffness of the jointed section to that of the jointless section reaches a certain value (greater than 1.0), the critical buckling load of the jointed composite wall is not less than that of the jointless composite wall, and simultaneously, the stiffness and strength conditions can also be satisfied. Therefore, the joint of the specimen is designed based on the stability condition of the silo.

According to the abovementioned structural scheme of the prefabricated underground silo, the arc length of a single steel plate concrete prefabricated block is $2.2 \mathrm{~m}$, and the vector height is less than $0.05 \mathrm{~m}$. If the specimen is manufactured using arc processing, although more in line with the actual scenario, it will be necessary to make a special test loading device system to exert the circumferential axial force and realize the actual boundary conditions. The literature [14] shows that the toggle joint 


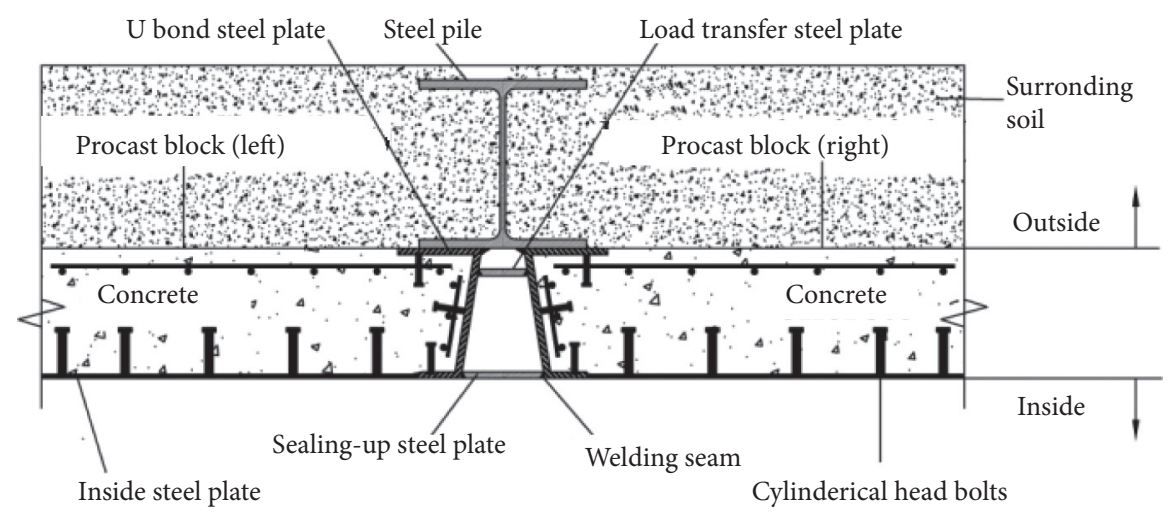

Figure 3: Vertical joints of composite wall.

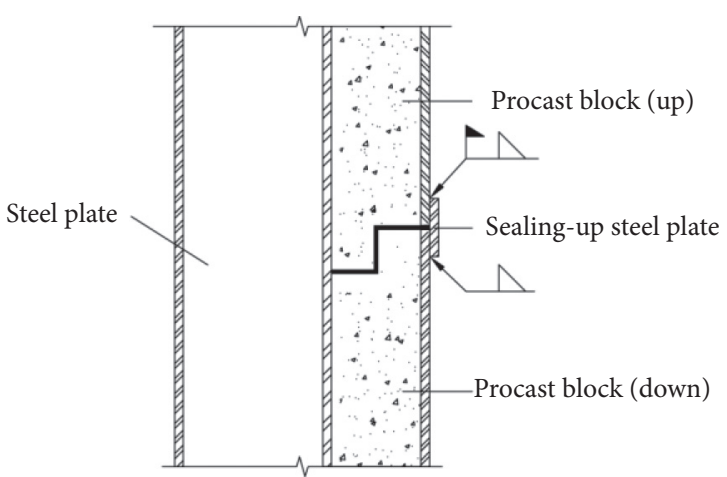

FIgURE 4: Circumferential joints of composite wall.

can be replaced by the direct joint. In this experiment, a $1: 1$ full-scale flat specimen is used, and a "straight specimen instead of a curved one" is used to conduct the experiment; this helps save experiment costs.

4.2. Specimen Fabrication. Dividing specimens into jointless and jointed categories, two jointless specimens and four jointed specimens were fabricated. One jointless specimens and two jointed specimens were used for flexural experiment; the other three specimens were used for the compressive force experiment.

The jointless specimens are numbered SC-M1 and SC$\mathrm{N} 1$; the sizes and structures of the specimens are shown in Figure 5. The jointed specimens are SC-M2, SC-M3, SC-N2, and SC-N3. The sizes and structures of the jointed specimens are shown in Figure 6. SC-M is a flexural specimen, and SC$\mathrm{N}$ is compressive specimen; the thickness of the waterproof steel plate with the jointed specimen is enlarged based on the finite element simulation analysis to improve its bearing capacity and safety reserve.

The concrete strength grade of each specimen is C40; the steel grades of steel plate and steel pile are Q345B, and the studs of cylinder head are ML15. According to the design requirements, all steel components are processed and manufactured in batches in the steel structure processing plant and welded by a stud-welding machine for stud head bolts and steel plates. The steel components of each specimen are used as bottom molds, and then, concrete is poured and maintained for $30 \mathrm{~d}$. Finally, the prefabricated blocks and steel piles are welded together in a simulated field construction (vertical welding) to complete the fabrication of the specimens.

\section{Flexural Experiment}

5.1. Experiment Loading. The flexural experiment is conducted using simply supported ends and two-point symmetrical loading. The loading diagram of the flexural experiment is shown in Figure 7. Two hydraulic servo pressure loading systems, including loading beams, were selected from the Civil Engineering Experimental Center of Henan University of Technology. As shown in Figure 8, the maximum load provided by a single pressure testing machine is $500 \mathrm{kN}$, and the test data are automatically collected by a computer.

Positioning before leveling when stalling specimens and preloading before formally loading ensures the normal work of the support, acquisition instrument, displacement meter, and so on, and it reduces the fabrication defects and system errors of the component itself. The calculation in the empty silo condition shows that the maximum pressure at the bottom of the wall is $292 \mathrm{kN} / \mathrm{m}^{2}$, and the maximum target loading value at each loading point is $270 \mathrm{kN}$. The loading speed is $30 \mathrm{kN} / \mathrm{min}$ in nine stages.

5.2. Experiment and Measurement Points. Two Donghua DH3816N acquisition instruments (60 channels each) and a DSDAH signal acquisition and analysis system were used for data acquisition. The experiment instruments included a YHD-50/100 displacement meter, steel plate, concrete strain gauge, etc.

The vertical displacement measurement points of jointed and jointless specimens in flexural experiments are in the same position. The vertical displacement measurement points of specimens are arranged as shown in Figure 9, and the displacement meters in the test site are arranged as shown in Figure 10. To obtain the stress distribution of the specimens and investigate whether the strength of the specimens and their joints meet the engineering requirements, strain gauges are arranged on the specimens. The arrangement of strain measurement points for jointless 


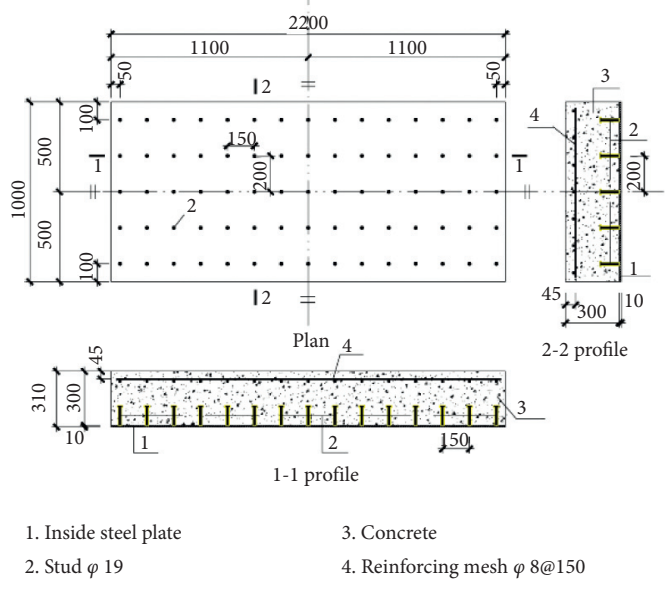

(a)

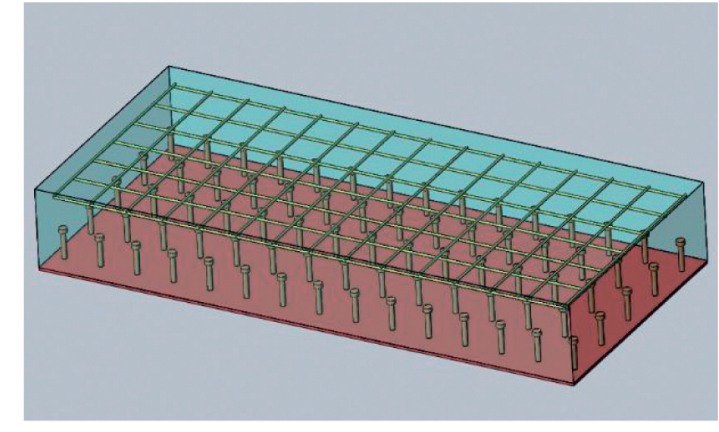

(b)

Figure 5: Size and structure of the jointless specimens (unit: $\mathrm{mm}$ ).

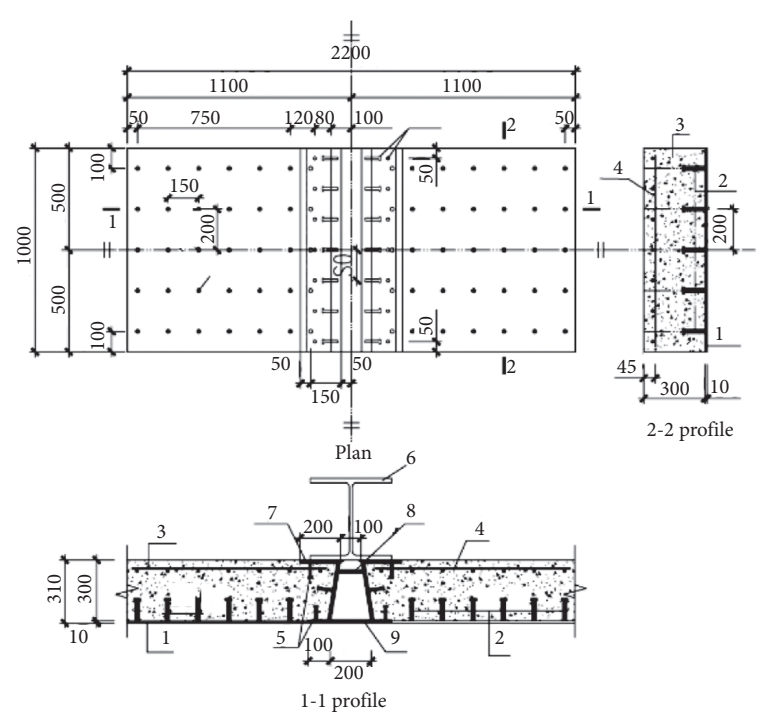

1. Inside steel plate

2. $\operatorname{Stud} \varphi 19$

3. Concrete

4. Reinforcing mesh $\varphi$ 8@150

5. $\operatorname{Stud} \varphi 13$
6. Steel pile $\mathrm{HW} 400 \times 400 \times 13 \times 21$

7. Outside bound plate $(16 \mathrm{~mm})$

8. Load transfer steel plate $(20 \mathrm{~mm})$

9. Sealing-up steel plate $(18 \mathrm{~mm})$

(a)

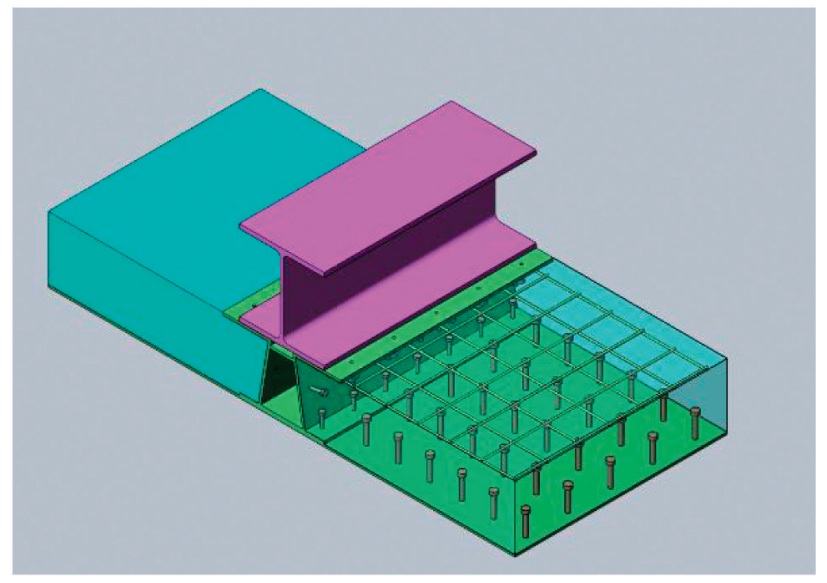

(b)

FIGURE 6: Size and structure of the jointed specimens (unit: $\mathrm{mm}$ ).

specimens in flexural experiments is shown in Figure 11 and for jointed specimens in Figure 12. In addition to comparing the measurement points, the measurement points of jointed specimens are encrypted in the joint area.

5.3. Experimental Result and Analysis. During the entire loading process, none of the specimens showed cracks, and they recovered after unloading. The joints such as steel plate and welds remained intact. The steel plate and concrete were joined together by bolts without separating and deformed synergistically.

Taking the average values of $\mathrm{C} 1, \mathrm{C} 2$, and $\mathrm{C} 3$ as the midspan deflection, the load-midspan deflection curves of the three specimens are shown in Figure 13. The deflection values of the 3 specimens when the load reaches the maximum target value of $270 \mathrm{kN}$ are listed in Table 1 . Considering the displacement value of the longitudinal center line at the bottom of the specimen at this time, the deflection curves of the three specimens are drawn as shown in Figure 14. The measuring points on both sides of the center line can be used as the reference values of the corresponding center line and the replacement values of individual distorted measuring points.

Figure 13 shows that the midspan deflection increases linearly with the increase in load, which indicates that the specimen is in the stage of elastic deformation during the loading process and no plastic deformation occurs. Figure 14 


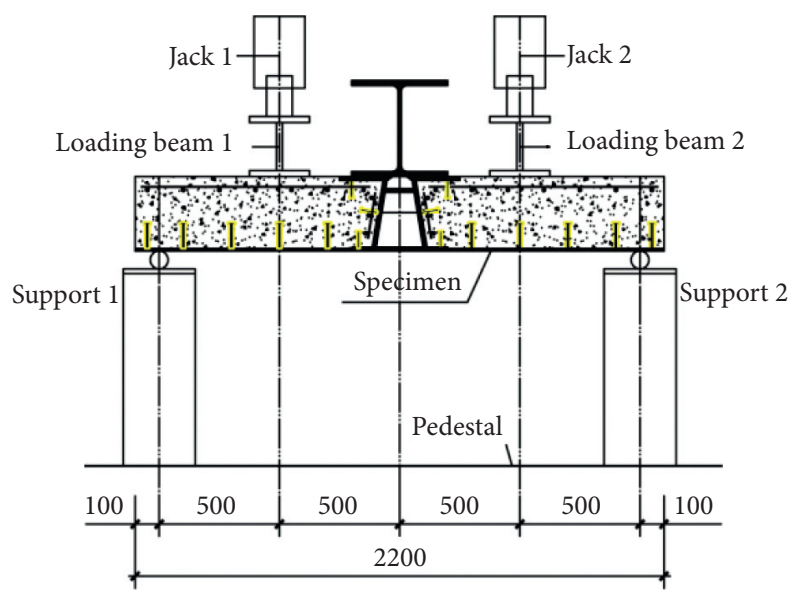

FIGURE 7: Loading diagram of the flexural experiment.

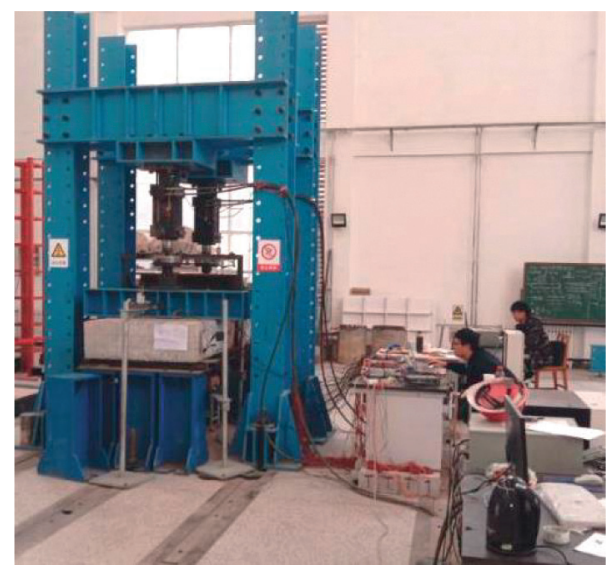

FIGURE 8: Field loading and testing of the flexural experiment.

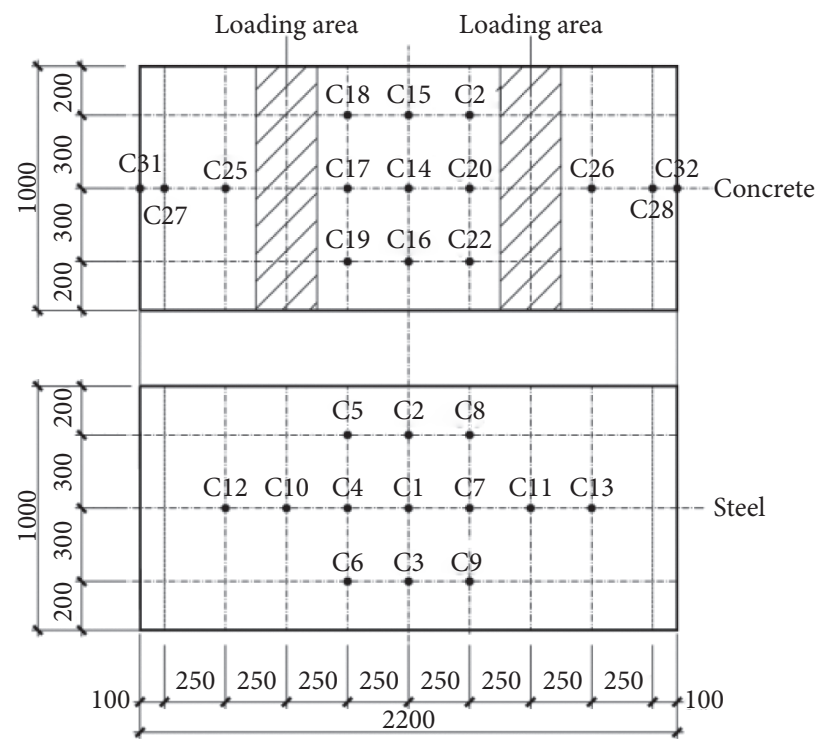

FIGURE 9: Vertical displacement measurement points arrangement of flexural experiment specimens.

shows that the midspan deflection of each specimen is the largest, and the deformation of left and right sides is symmetrical, which conforms to the deformation law of the two-point bending members. The existence of the joint does not change its deformation law, and therefore, it is a reliable connection method. Further, both Figures 13 and 14 indicate 


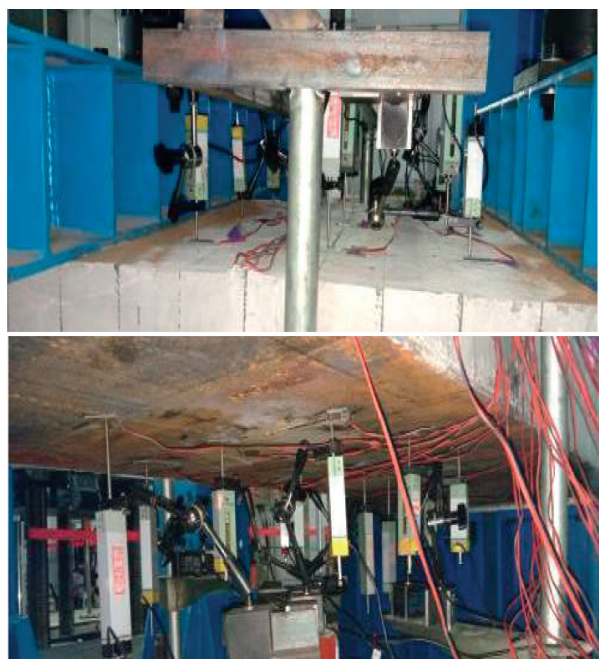

Figure 10: Field displacement meter arrangement of flexural experiment.

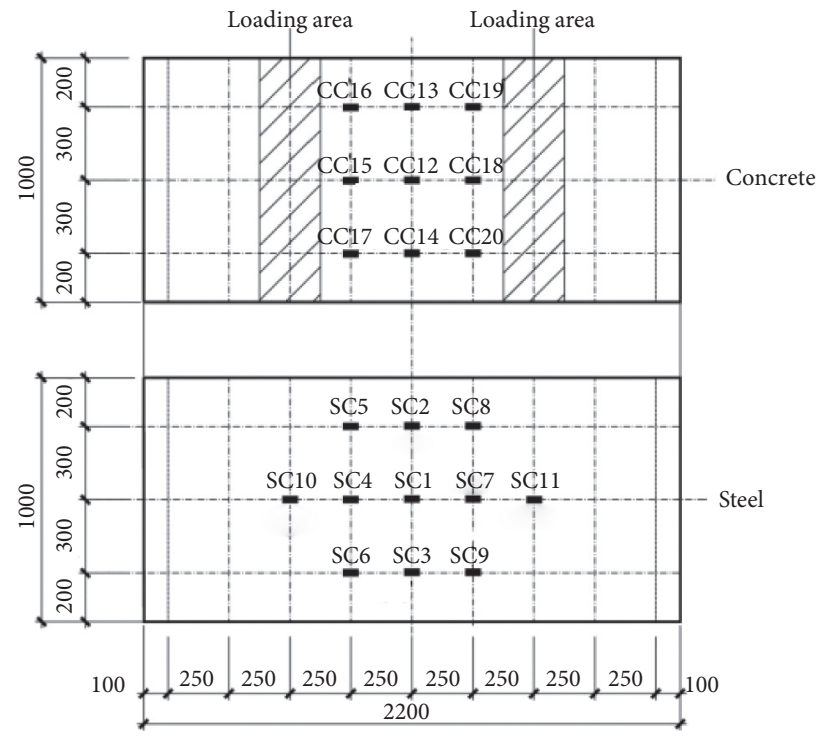

FiguRE 11: Arrangement of strain measuring points for jointless specimens in flexural experiment (unit: mm).

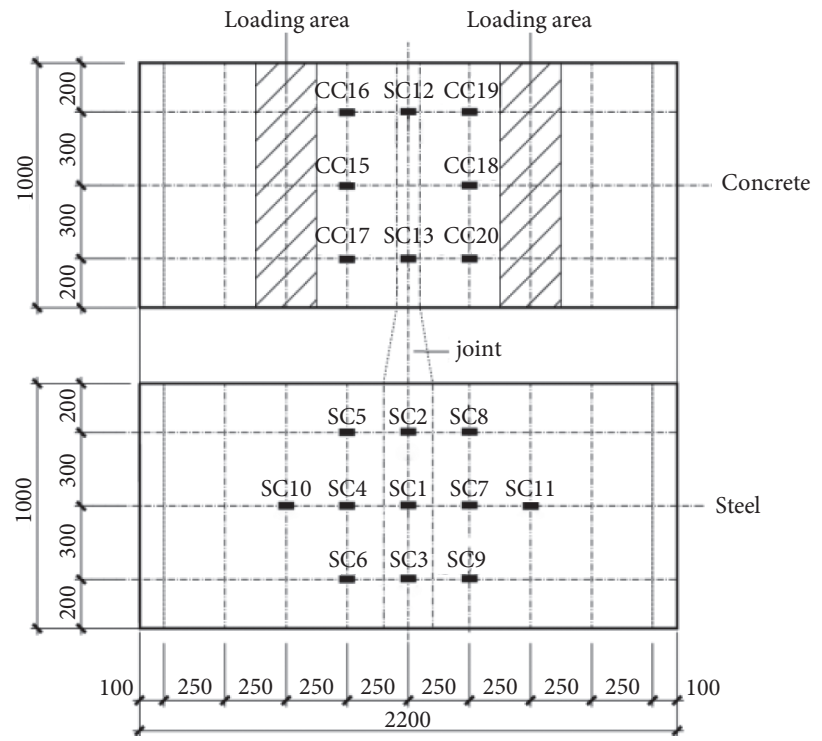

FIGURE 12: Arrangement of strain measuring points for jointed specimens in flexural experiment. 


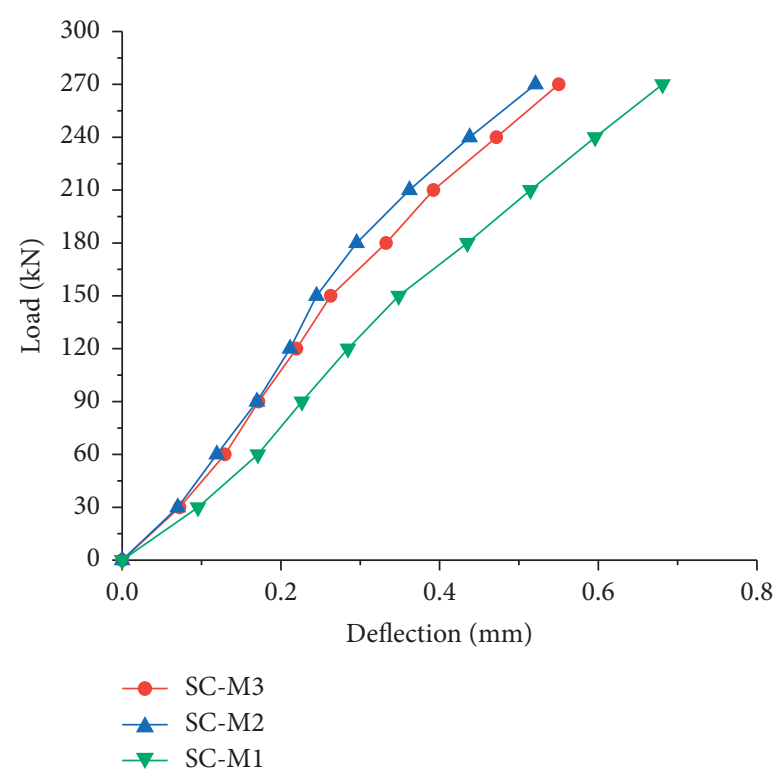

FIgURE 13: Load-mid-span deflection relationship of flexural specimens.

TABLE 1: Midspan deflection of flexural specimens.

\begin{tabular}{lccc}
\hline $\begin{array}{l}\text { Specimen } \\
\text { number }\end{array}$ & $\begin{array}{c}\text { Load } \\
(\mathrm{kN})\end{array}$ & $\begin{array}{c}\text { Midspan deflection } \\
(\mathrm{mm})\end{array}$ & Notes \\
\hline SC-M1 & 270 & 0.69 & $\begin{array}{c}\text { Without } \\
\text { joints }\end{array}$ \\
SC-M2 & 270 & 0.57 & With joints \\
SC-M3 & 270 & 0.52 & With joints \\
\hline
\end{tabular}

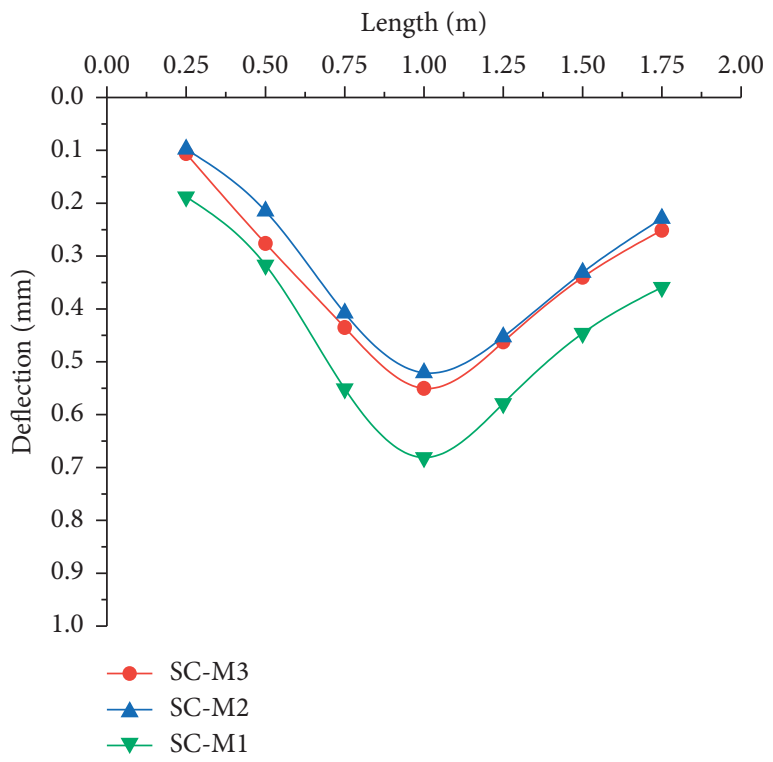

FIgURE 14: Deflection curves of flexural specimens.

that the deformation laws of the three specimens are the same, and the deflection values of the two specimens with joints are relatively small, which are smaller than those of the specimens without joints. This suggests that the flexural stiffness of jointed specimens is greater than that of jointless specimens, and the flexural stiffness of joints is greater than that of walls, as is consistent with the design principles and requirements of joints.

Based on the strain test data, the load-strain relationship curves and strain distribution diagram of jointless specimens SC-M1 are drawn, as shown in Figures 15 and 16, respectively. The load-strain curves of the jointed specimens SC-M2 is shown in Figure 17, and the average strain distributions of the jointed specimens SC-M2 and SC-M3 are shown in Figure 18. The maximum tensile stress of steel plate and the maximum compressive stress of concrete are summarized in Table 2. The test results show that the transverse strain of the steel plate and concrete increases linearly with the increase in load, and the specimens are always under elastic stress. The maximum strain of steel plate and concrete is far less than their respective limit linear strain values (concrete ultimate compressive strain 0.003 ; steel plate ultimate tensile strain 0.01); based on the comparison of the side strain of the steel plate in Figures 16 and 18, the strain of jointed specimens appears to change abruptly at the midspan. However, the strain value at the midspan decreases. Therefore, although the stress distribution of the specimens is changed, the local stress concentration occurs, and the maximum position is different because of the joints, whereas the maximum value is less than the allowable value of the project. The experiments show that the designed joint and its fabrication can meet the strength requirements, and the design is reasonable and the working performance is good.

\section{Compressive Experiment}

6.1. Loading Scheme. The compressive specimens are loaded under axial compression. The loading diagram of compressive experiment is shown in Figure 19. The hydraulic servo shear compression column loading system of the Civil Engineering Experimental Center of Henan University of 


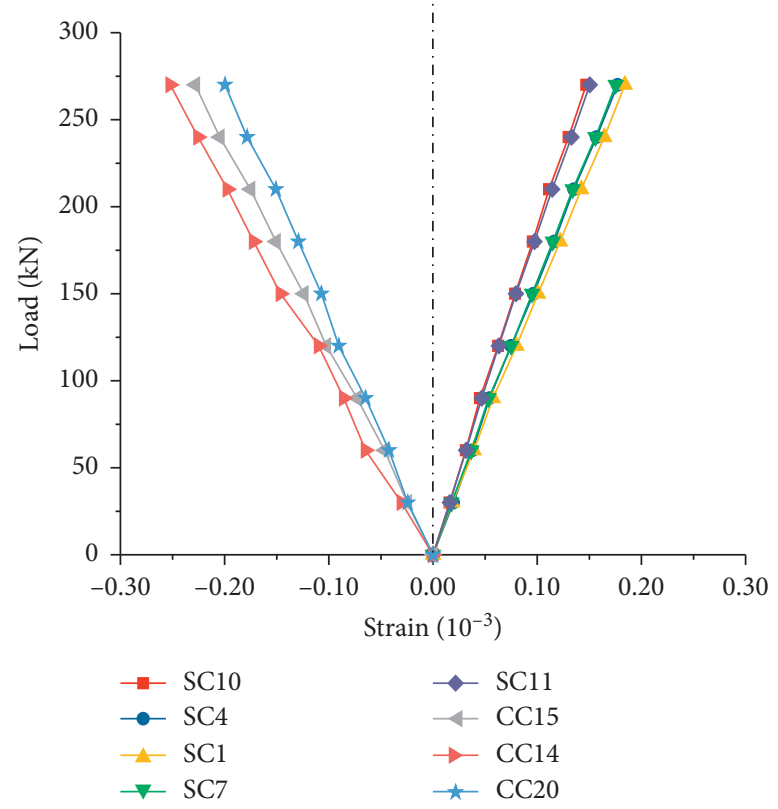

FIGURE 15: Load-strain relationship of SC-M1 in flexural experiment.

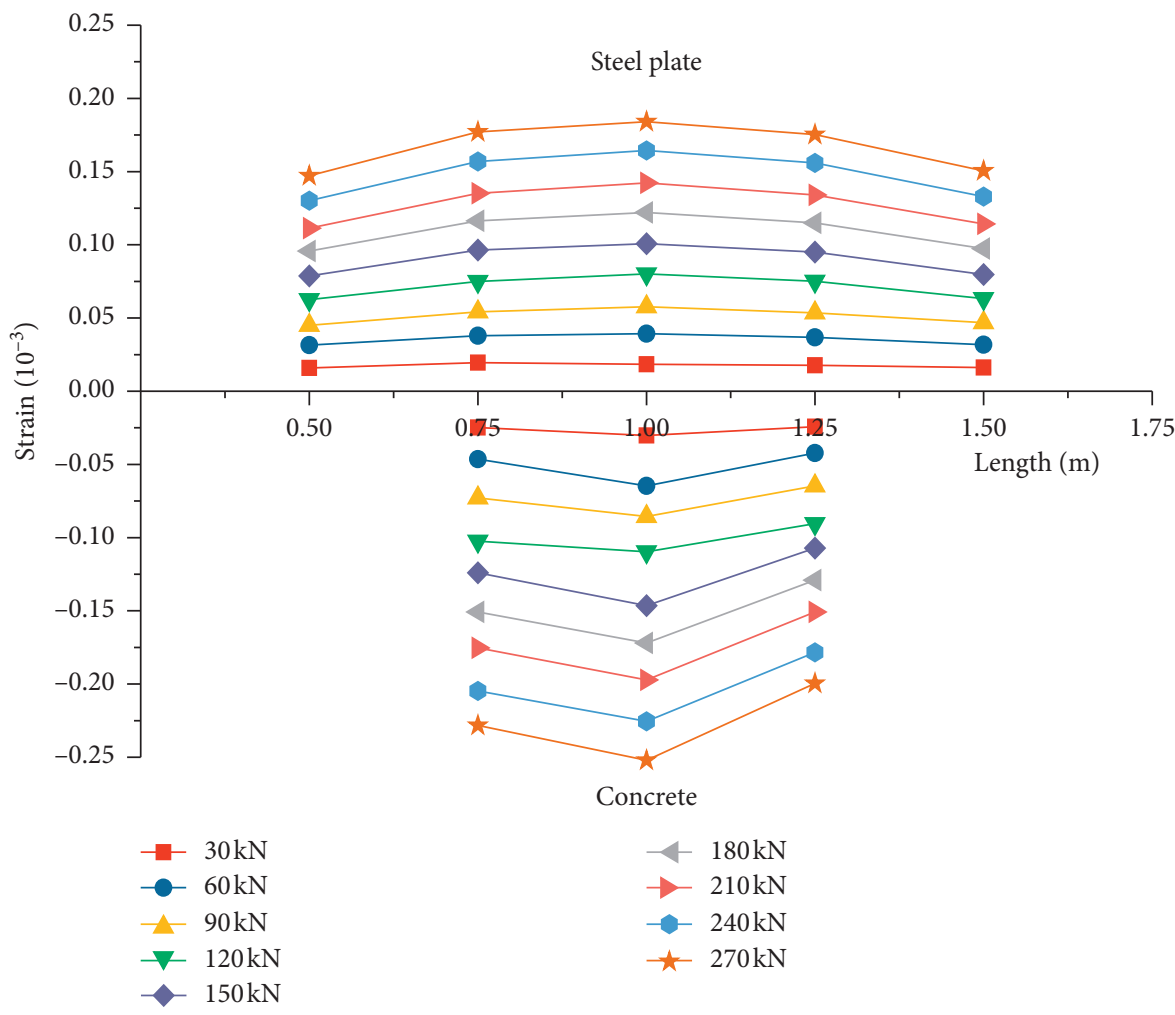

FIGURE 16: Strain distribution of SC-M1 in flexural experiment.

Technology was employed. The maximum pressure provided by the testing machine is $1200 \mathrm{t}$. The field loading and testing of the compressive experiment is shown in Figure 20. The maximum load target value of compressive experiment is $5000 \mathrm{kN}$, which is loaded in 25 stages, and the loading speed is $2 \mathrm{kN} / \mathrm{s}$. The preparation for specimen installation, leveling, instrument debugging, and preloading before formal loading are the same as in flexural experiments; therefore, they are not repeated here.

6.2. Experiment and Measurement Points. Data acquisition systems for compressive experiment and flexural experiment 


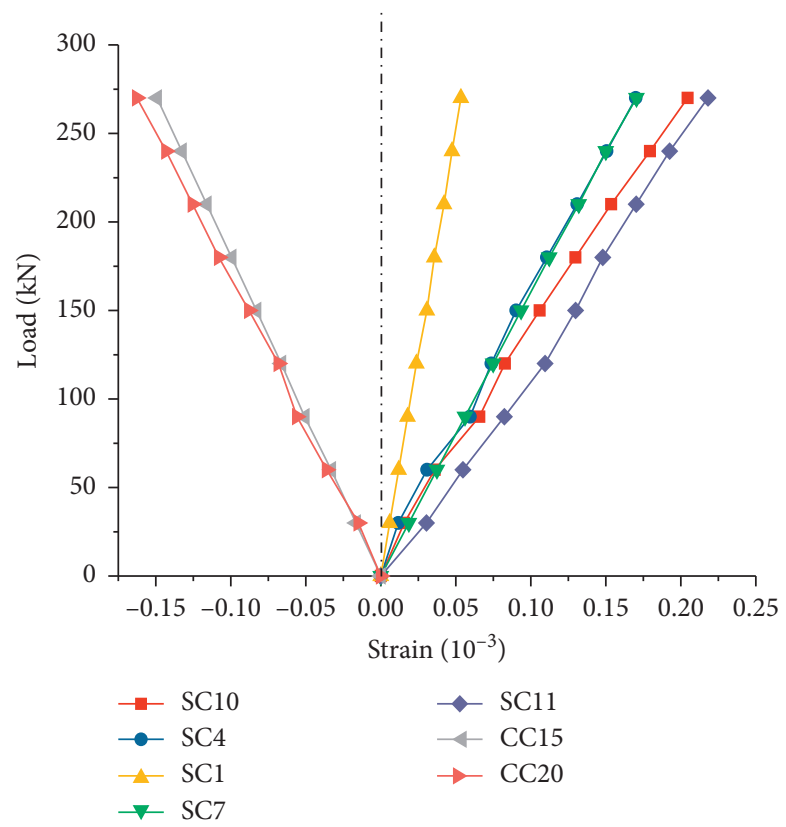

FIGURE 17: Load-strain relationship of SC-M2 in flexural experiment.

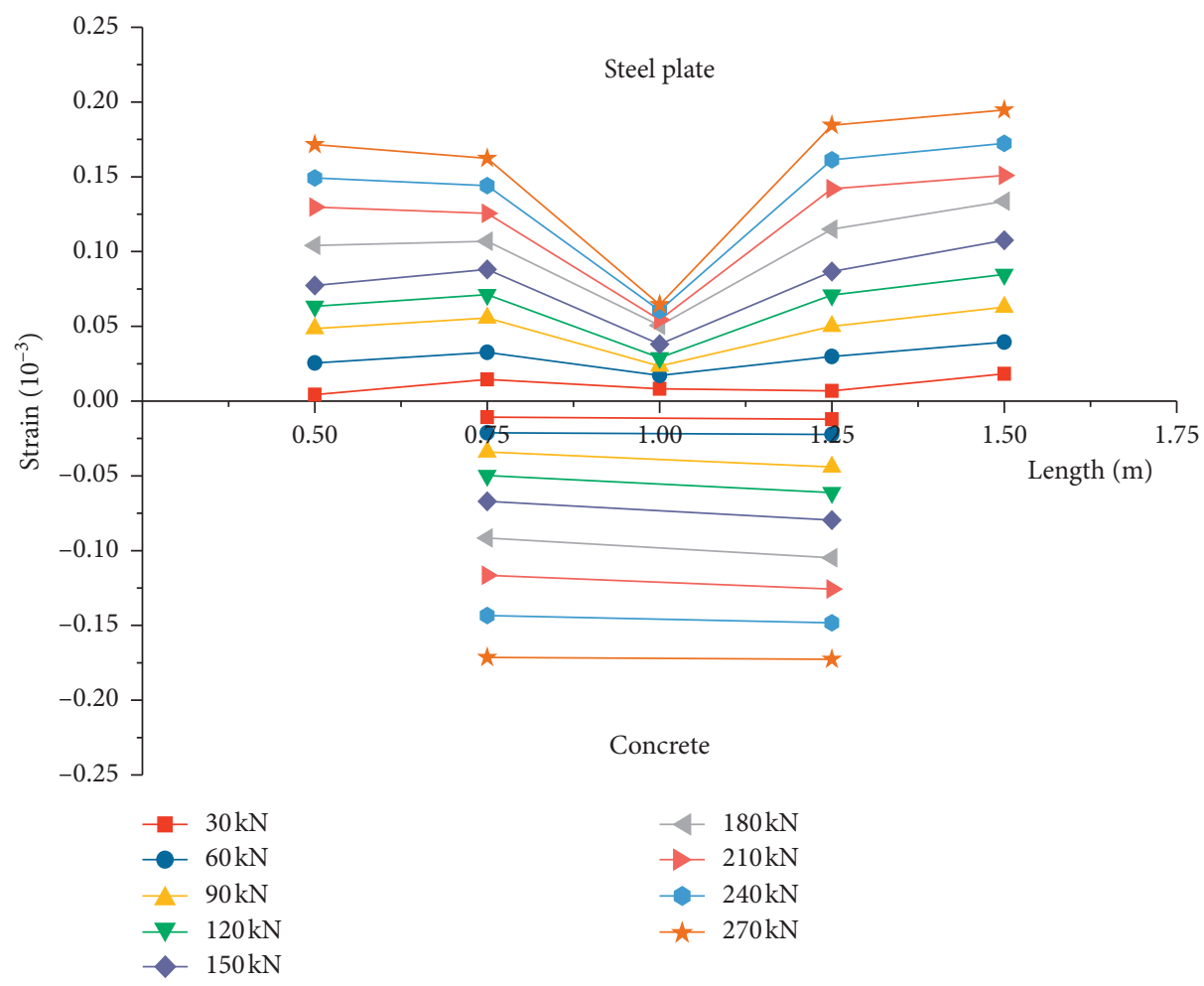

FIGURE 18: Average strain distribution of jointed specimens in flexural experiment.

TABLE 2: Extreme stress of bending test specimens.

\begin{tabular}{lccc}
\hline Specimen number & Extreme stress of steel plate (location) $(\mathrm{MPa})$ & Extreme stress of concrete (location) $(\mathrm{MPa})$ & Notes \\
\hline SC-M1 & $36.8($ midspan) & $-6.85(0.75 \mathrm{~m})$ & Without joints \\
SC-M2 & $43.6(1.5 \mathrm{~m})$ & $-4.88(1.25 \mathrm{~m})$ & With joints \\
SC-M3 & $39.7(1.25 \mathrm{~m})$ & $-5.81(0.75 \mathrm{~m})$ & With joints \\
\hline
\end{tabular}

Note: permissible stress value for Q345 steel plate is $310 \mathrm{MPa}$ (less than $16 \mathrm{~mm}$ )/295 MPa and for C40 concrete $19.1 \mathrm{MPa}$ (compression)/1.71 MPa (tension). 


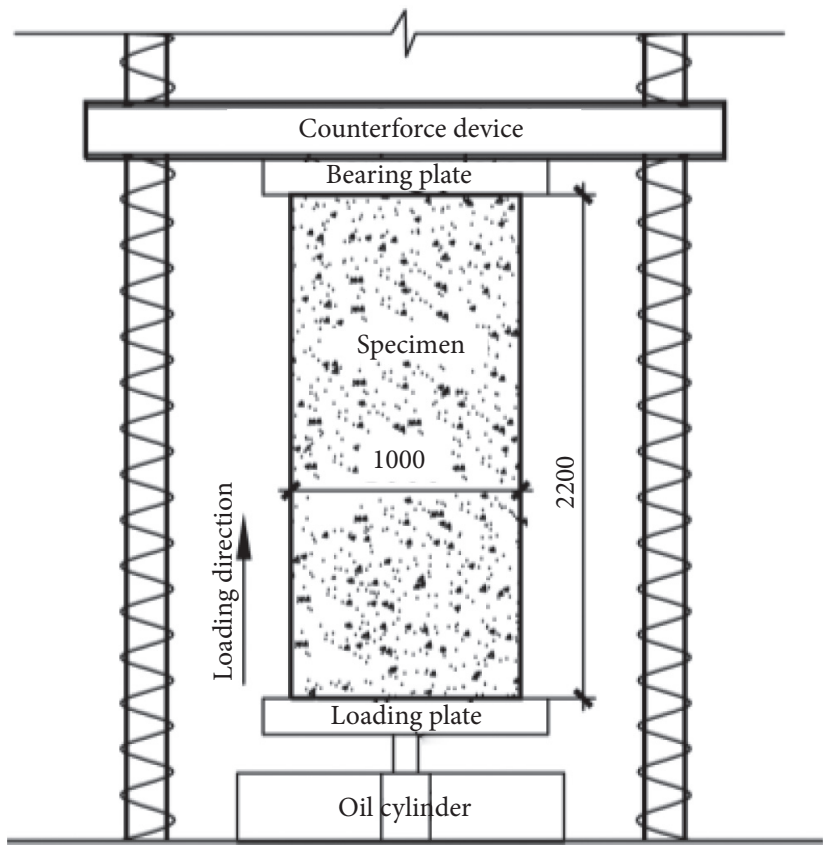

FIGURE 19: Loading diagram of the compressive experiment.

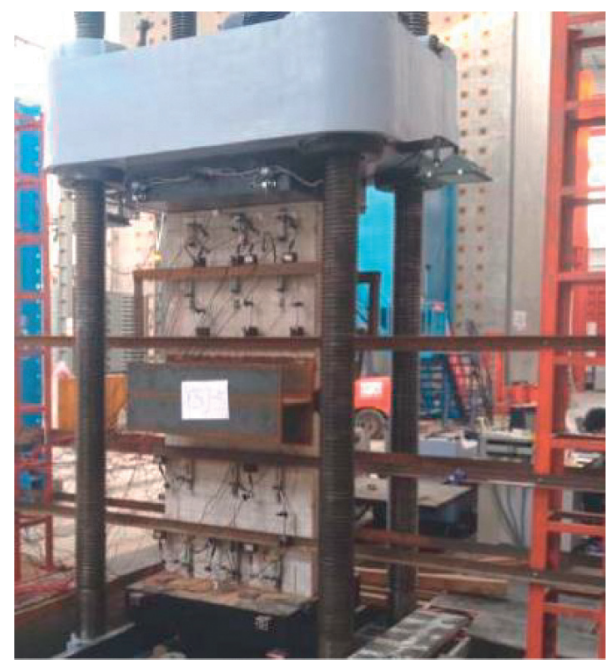

Figure 20: Field loading and testing of the compressive experiment.

are equipped with the same type of equipment and instruments. The displacement measurement points of jointed and jointless specimens in compressive experiment are arranged in the same way as shown in Figure 21; the arrangement of displacement meters in Figure 22; the arrangement of strain measuring points for jointless specimens in Figure 23; and for jointed specimens in Figure 24.

6.3. Experimental Result and Analysis. During the entire loading process, no obvious structural cracks were found in all specimens, and only local cracks appeared at the boundary of the support points at both ends. After unloading, the specimens could be completely restored to their original state, and the specimens were basically intact, thereby indicating that the entire loading process of the specimens was in the stage of elastic deformation; the welds were intact, and the welds were sufficiently strong. The steel plate and concrete are joined together by bolts; they are not separated and can deform synergistically.

In the compressive experiment, the displacement difference between the bottom and the top of the specimen is used as the total longitudinal compressive deformation of the specimen. The load-deformation curves of the compressive specimens drawn from the test data are shown in Figure 25. Further, this figures indicates that the total compressive deformation of the specimens increases linearly with the increase in load, which indicates that the specimens are always in a stage of elastic deformation. Four rows of measuring points are arranged along different heights of the specimens. Under the last 


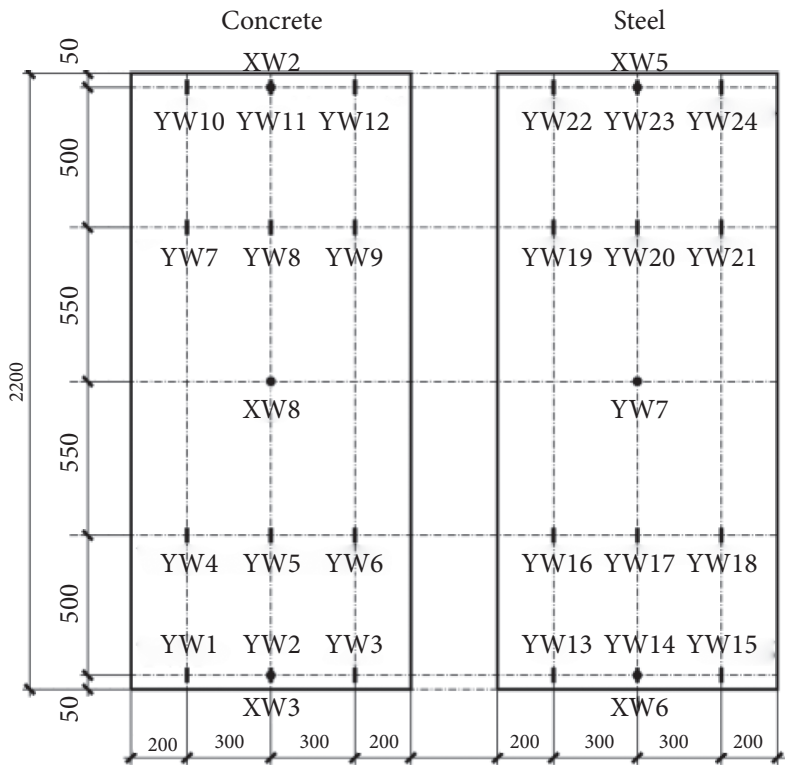

FIGURE 21: Arrangement of displacement measuring points for compressive experiment specimens.
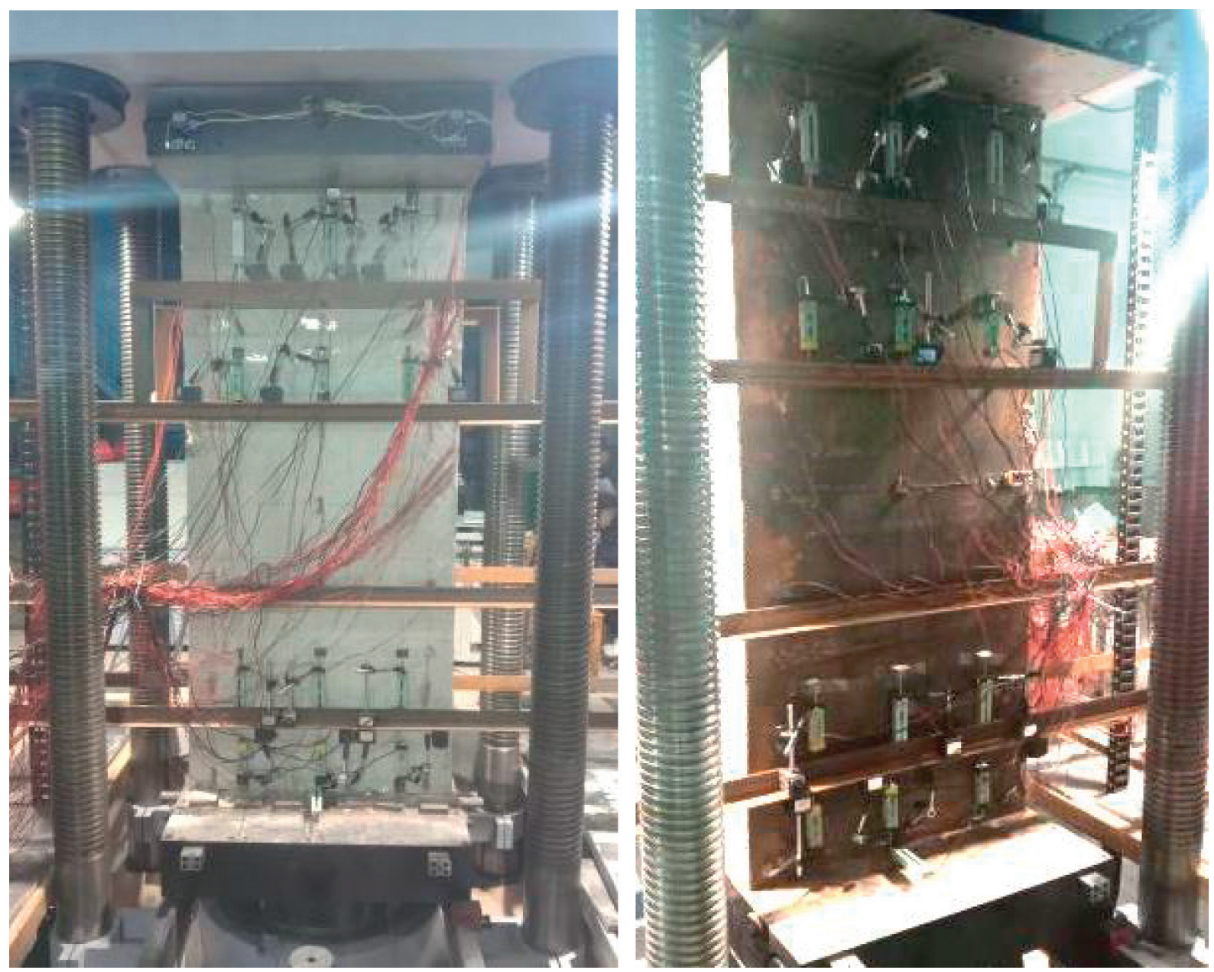

FIGURE 22: Field displacement meter arrangement for compressive experiment.

stage load, the difference between the average displacement of six measuring points at a certain altitude and the average displacement of six measuring points at the top is regarded as the longitudinal compressive deformation of this position. From this, the load-deformation relationship of measuring points at different heights is obtained as shown in Figure 26. This figure shows that the load- deformation relationship at different height points tends to be linear, which indicates that the deformation of specimens is approximately linear and conforms to the deformation law of axially compressed members. The total longitudinal compression deformation of the specimens under the last stage load reaches the maximum value, as summarized in Table 3 . Table 3 indicates that the 


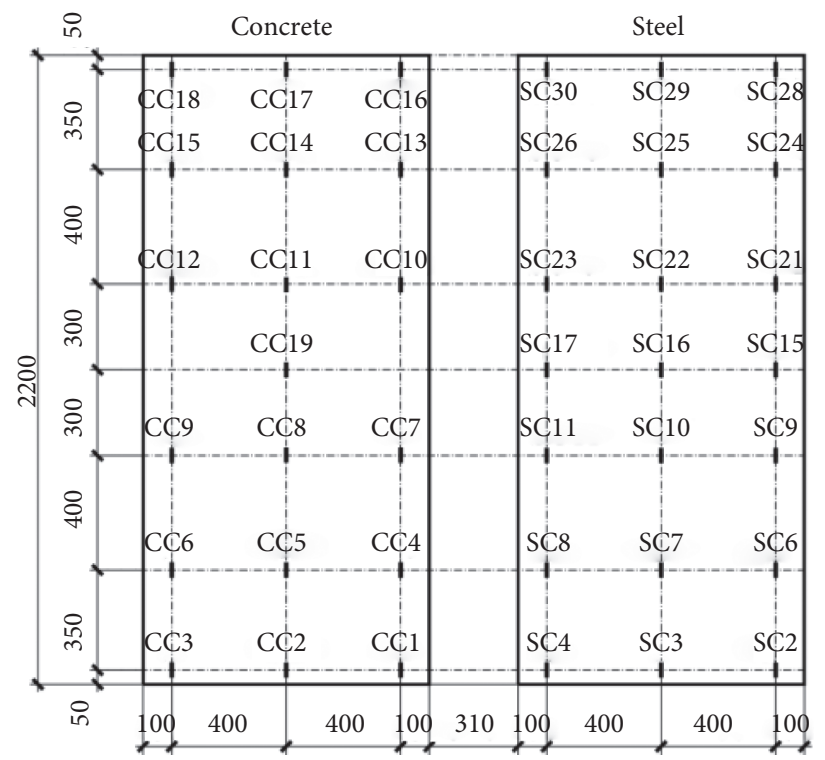

FIGURE 23: Arrangement of strain measuring points for jointless specimens in compressive experiment.

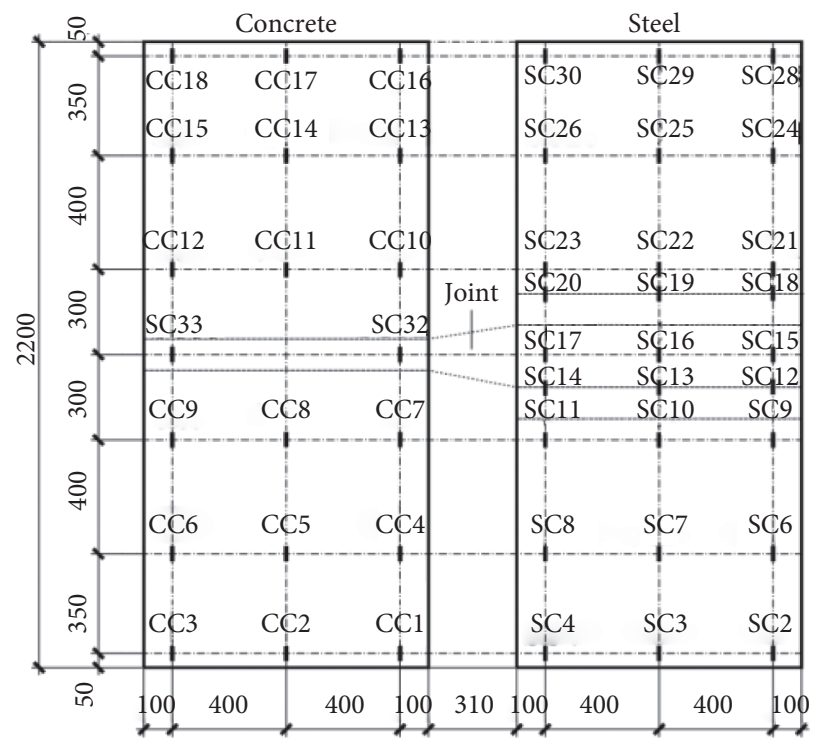

FIgURE 24: Arrangement of strain measuring points for jointed specimens in compressive experiment.

total longitudinal compressive deformation of jointed specimens is smaller than that of the jointless specimens, which indicates that the compressive stiffness of jointed specimens is not reduced by the existence of joints, and the former is not weaker than the latter.

Figures 27 and 28 show the load-strain relationship and strain distribution diagrams of jointless specimens SC-N1, respectively. With an increase in load, the transverse strain of the steel plate and concrete increases linearly and is in the elastic stage. Besides the local stress errors at both ends of the specimens, the stress distribution of steel plate and concrete is uniform. Figure 29 shows the load-strain relationship of the jointed specimens SC-N2, and the variation law is similar to that of jointless specimens SC-N1. Figure 30 shows the average strain distributions of jointed specimens SC-N2 and SC-N3. The variation trend is different from that of jointless specimens SC-N1. The maximum compressive stress of the steel plate and concrete for each specimen is summarized in Table 4. Noticeably, the joint changes the stress distribution of the specimen. However, the strain and stress of steel plate and concrete are far less than the allowable value, and the jointed specimens still have sufficient compressive capacity to satisfy the engineering requirements. In addition, by comparing the displacement and strain of jointed and jointless specimens, it 


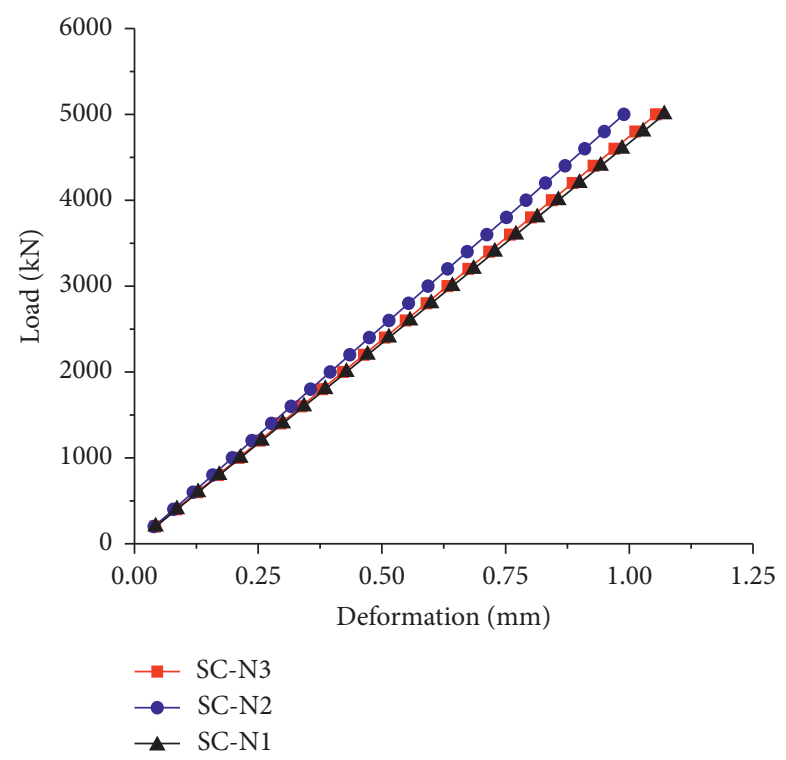

FIGURE 25: Load-deformation relationship of compressive specimens.

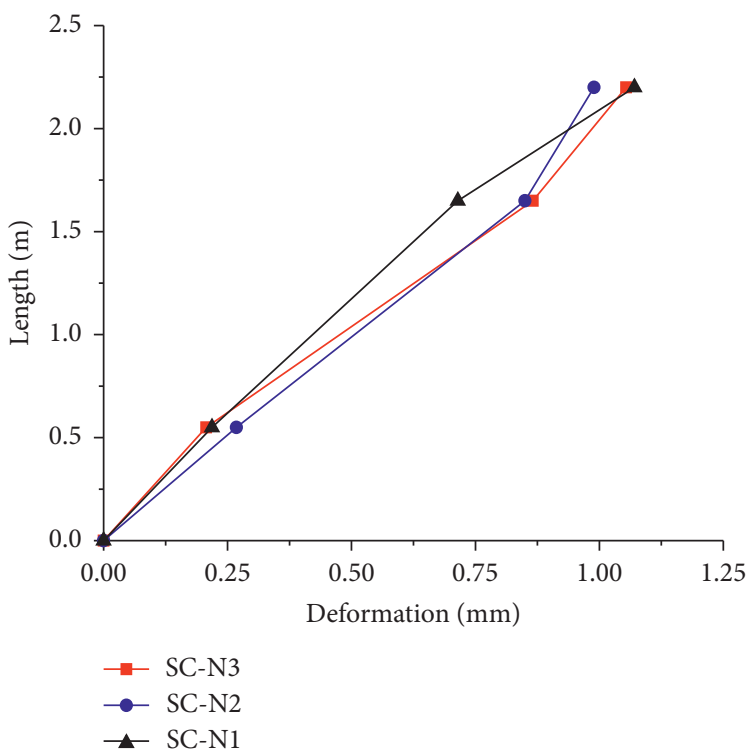

FIgURE 26: Load-deformation relationship at different heights.

TABle 3: Extreme deformation of compressive experiment specimens.

\begin{tabular}{lccc}
\hline Specimen number & Load $(\mathrm{kN})$ & Deformation $(\mathrm{mm})$ & Notes \\
\hline SC-N1 & 5000 & 1.07 & Without joints \\
SC-N2 & 5000 & 0.98 & With joints \\
SC-N3 & 5000 & 1.05 & With joints \\
\hline
\end{tabular}




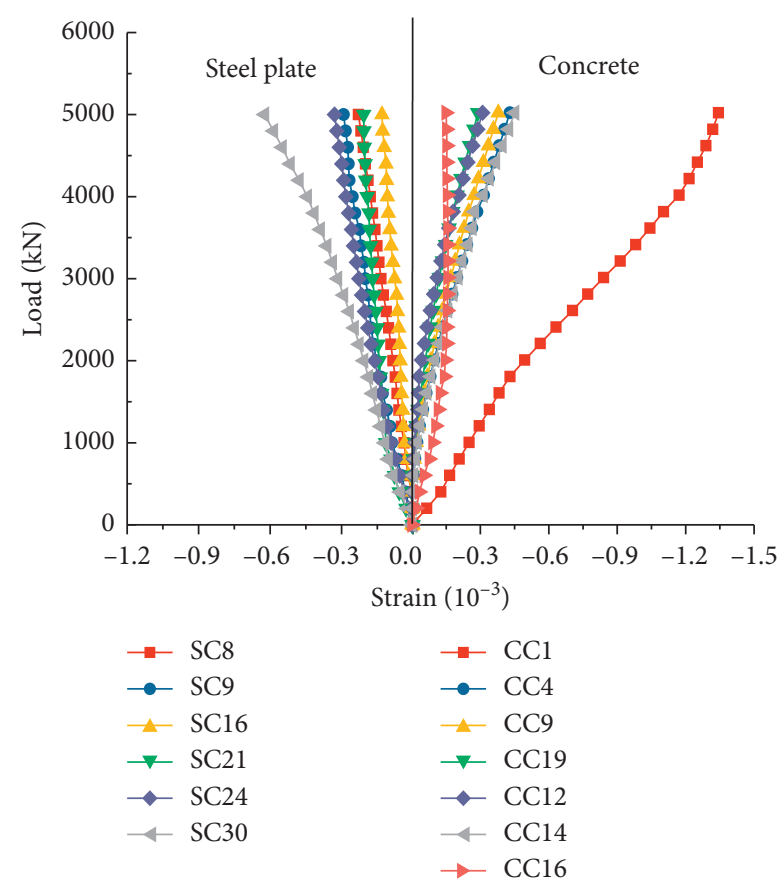

FIgURE 27: Load-strain relationship of SC-N1 in compressive experiment.

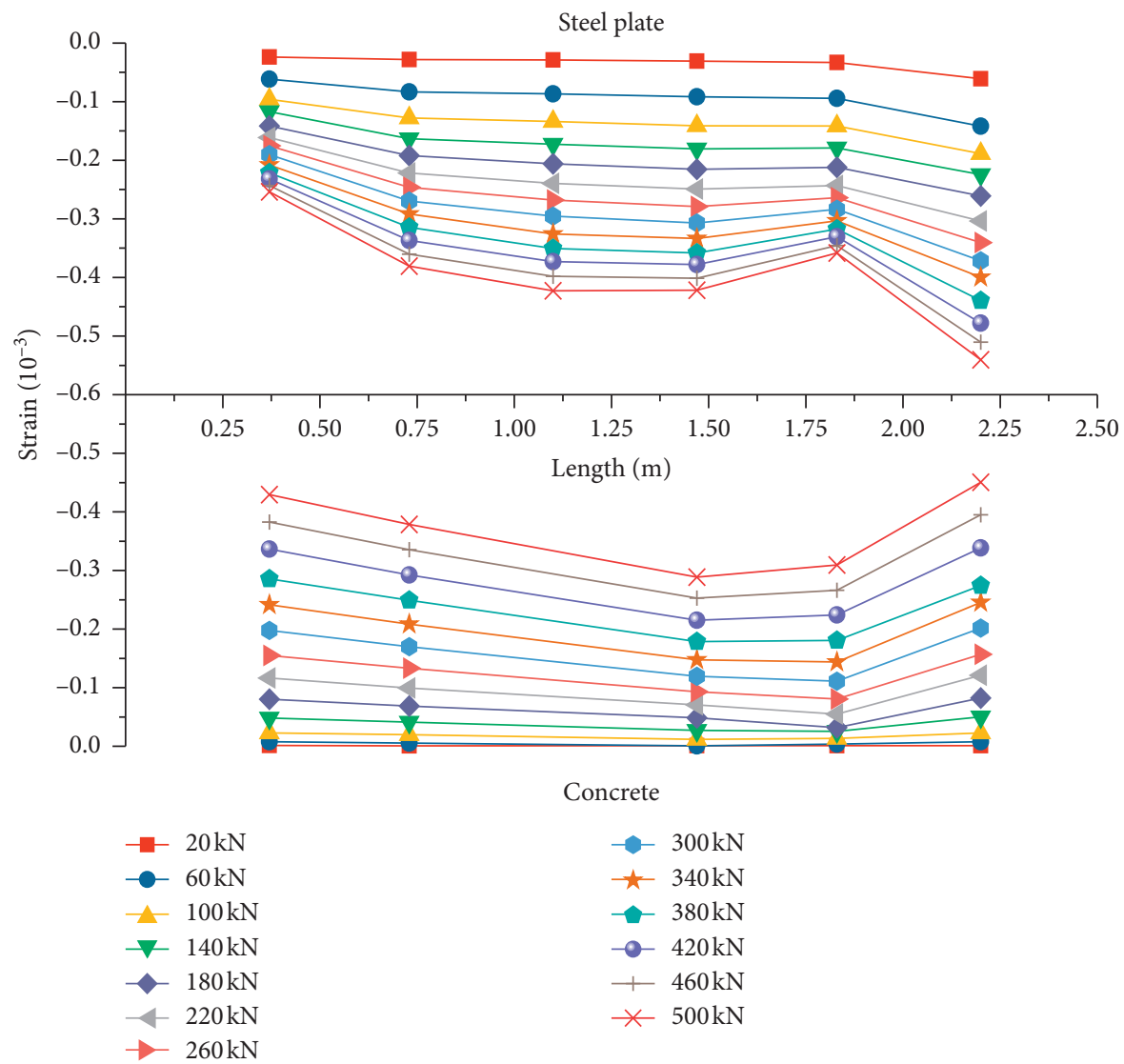

FIGURE 28: Strain distribution of SC-N1 in compressive experiment. 


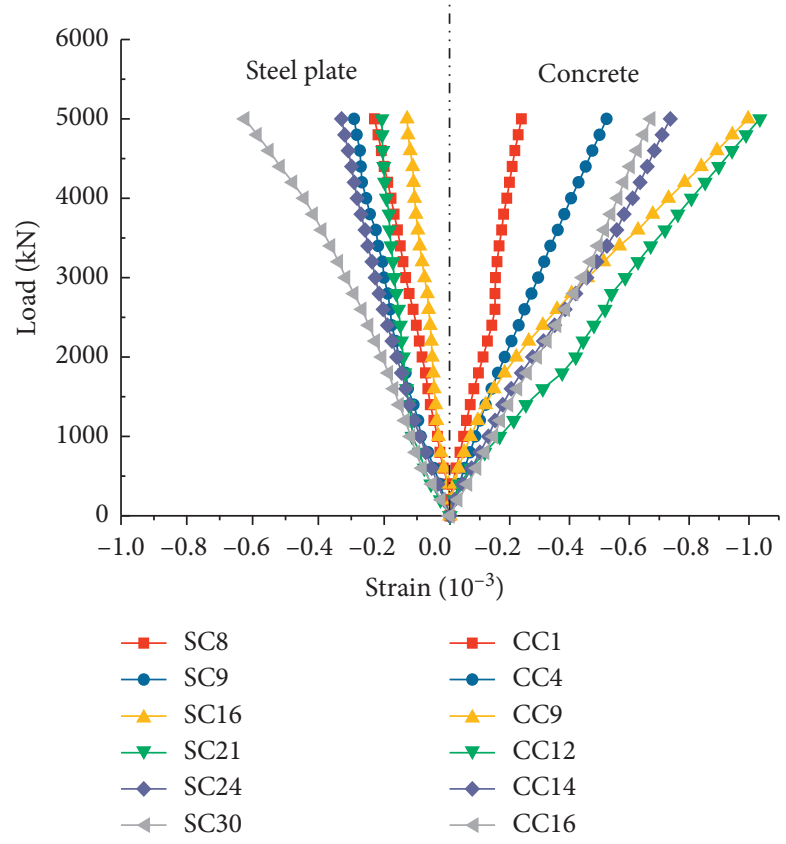

FIgURE 29: Load-strain relationship of SC-N2 in compressive experiment.

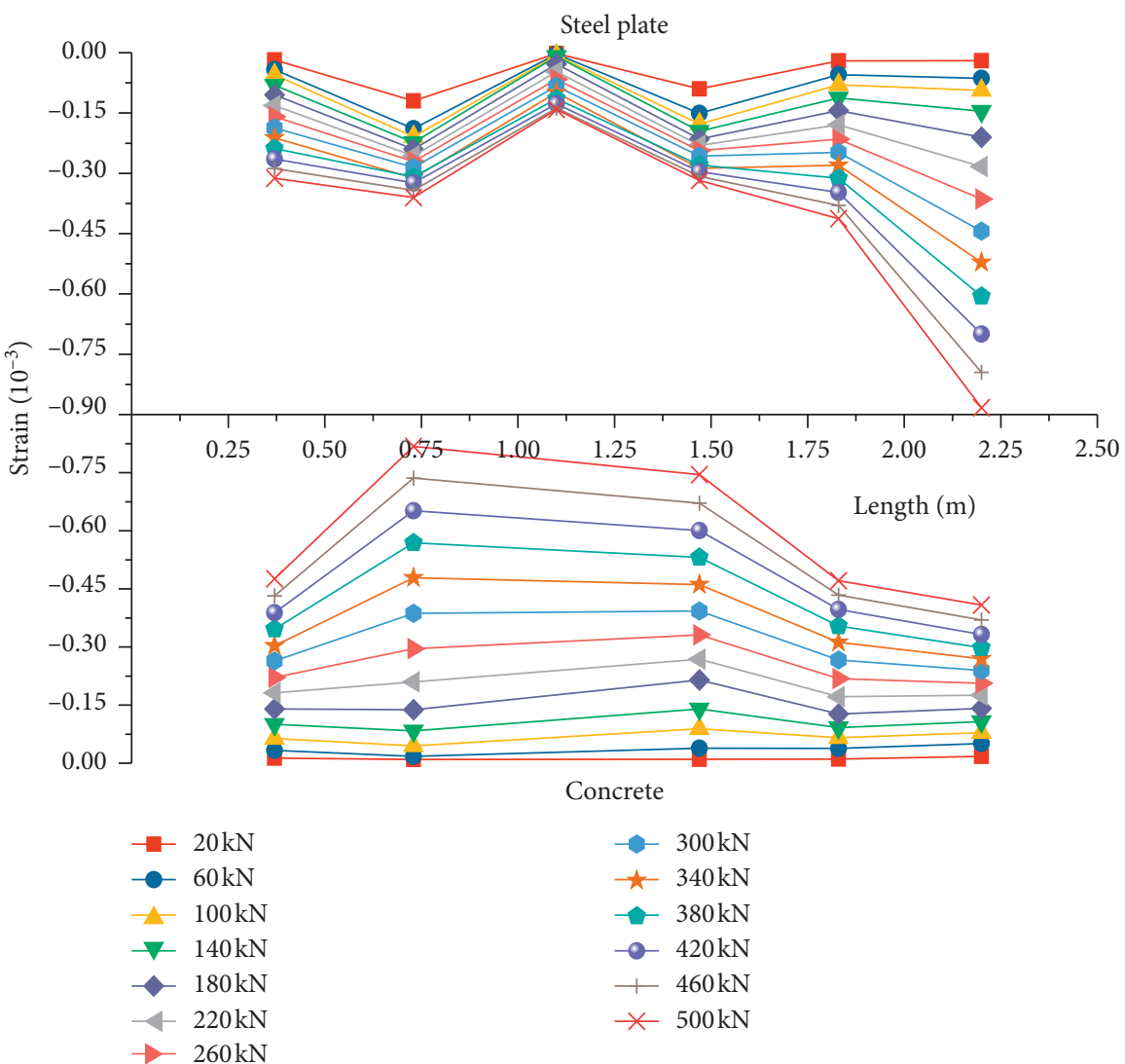

Figure 30: Average strain distribution of jointed specimens in compressive experiment. 
TABLE 4: Extreme stress of compressive experiment specimens.

\begin{tabular}{lccc}
\hline Specimen number & Extreme stress of steel plate (location) (MPa) & Extreme stress of concrete (location) (MPa) & Notes \\
\hline SC-N1 & -108.09 (top) & $-40.32($ bottom) & Without joints \\
SC-N2 & -228.62 (top) & $-19.14(\mathrm{~L} / 3)$ & With joints \\
SC-N3 & -124.66 (top) & $-31.09(2 \mathrm{~L} / 3)$ & With joints \\
\hline
\end{tabular}

could be concluded that the compressive design calculation of jointed specimens could be performed by using the design idea of "equivalent principle."

\section{Conclusion}

The following conclusions can be drawn from this study:

(1) Under the equivalent load of external water and Earth pressure, the steel plate and concrete of the designed specimens can work together with bolts, and the specimens did not appear to crack and were in the elastic stage. A composite wall has large stiffness and high bearing capacity, and the design is reasonable, safe, and reliable.

(2) The vertical joint of the steel plate concrete composite wall of the prefabricated underground silo has good working performance. After loading to the target load, the joint was not destroyed. Thus, it is a safe, reliable, and feasible joint connection method.

(3) The flexural and compressive properties of jointed and jointless specimens were almost the same. The stiffness and load-bearing capacity of the steel plate and concrete composite wall of prefabricated underground silo were not reduced by the existence of joints. The design idea of "equivalent principle" could be adopted; i.e., the combined wall design calculation with the joint was found to be equivalent to that without the joint.

(4) The straight specimen was used to replace the actual arc prefabricated block of the prefabricated underground silo wall in the experiment. "Straight instead of curved" considerably simplified the experiment, and the expected experimental results were obtained. This was an effective experimental method.

(5) The composite wall itself is a thin-walled cylinder structure. Considering the needs of practical engineering applications, full-scale specimens are used in this experiment. However, owing to the difficulty of loading and testing, the bearing capacity failure test has not yet been implemented. Subsequent research into the bearing capacity failure test needs to be conducted.

\section{Data Availability}

The data used to support the findings of this study are available from the corresponding author upon request.

\section{Conflicts of Interest}

The author declares no potential conflicts of interest regarding the publication of this article.

\section{Acknowledgments}

This work was supported by the National Ministry of Science and Technology 2014 special project for Food Public Welfare Industry "Research and Development of the New Warehouse Type and Technical Systems for Ecological Grain Storage" (Grant No. 201413007), the National Ministry of Science and Technology 2015 Special Research Project for Grain Public Welfare Industry "Study on Applicability Appraisal and Integration Standardization of New Warehouse Type and Supporting Process Equipment in Different Regions Based on Storage Ecology" (Grant No. 20151300103), and Special Fund Project of Basic Scientific Research Operating Expenses of Provincial Colleges and Universities (Grant No. 2016QNJH23).

\section{References}

[1] C. Chen, Research on China's Food Security Problens, Liaoning Normal University, Dalian, China, 2016.

[2] P. Zheng, Z. Q. Wang, and H. H. Yu, Brief History and Characteristics of Underground Storehouse in China, Cereals and Oils Processing, Beijing, China, 2009.

[3] Z. Q. Wang, Basic Theory and Design of Granary Architecture, Henan science and technology press, Zhengzhou, China, 2015.

[4] X. L. Xiong, L. B. Jin, and Z. Q. Wang, "Earth pressure and bearing capacity analysis on the wall of reinforced concrete underground granary," Journal of Applied Basic Science and Engineering, vol. 32, pp. 103-114, 2016.

[5] Z. Q. Wang, C. L. Zhou, Y. G. Ding et al., "Anti-floating design of cylindrical underground granary," Journal of Henan University of Technology (Natural Science Edition), vol. 34, pp. 90-93, 2013.

[6] L. B. Jin, F. X. Liu, and D. J. Tian, "Anti-floating test in construction and closed-water test process of underground reinforced concrete silos," Journal of Henan University of Technology (Natural Science Edition), vol. 38, pp. 105-108+128, 2017.

[7] K. Feng, C. He, and S. L. Xia, "Prototype experimental study on the effective lateral stiffness of shield tunnel structure with large section," Journal of Geotechnical Engineering, vol. 33, pp. 1750-1758, 2011.

[8] K. Feng, C. He, and Z. X. Su, "Experimental study on structural failure of nanjing yangtze river tunnel prototype," Journal of Southwest Jiaotong University, vol. 46, pp. 564-571, 2011.

[9] C. He, K. Feng, and Z. X. Sun, "Development and application of loading test system prototype structure for underwater shield tunnel with large cross-section," Chinese Journal of Rock Mechanics and Engineering, vol. 30, pp. 254-266, 2011.

[10] L. Lu, Y. Q. He, X. L. Bi et al., "Research on the experimental methods of whole-scale and whole-ring shield-driven tunnel lining," Structural Engineers, vol. 32, pp. 154-162, 2016. 
[11] T. Y. Ren, "Experimental study on the flexural mechanical properties of steel plate-concrete reinforced tube sheet," in Proceedings of the 2017 Annual Conference of China Civil Engineering Society, Shanghai, China, 2017.

[12] L. Lu, X. Lu, and P. Fan, "Full-ring experimental study of the lining structure of shanghai changjiang tunnel," Journal of Civil Engineering and Architecture, vol. 5, pp. 732-739, 2011.

[13] L. Zhang, R. Su, C. He et al., "Experimental study on the flexural full-size resistance of large-section shield tunnel segment joint under pure compressive bending," Tunnel Construction, vol. 40, pp. 997-1003, 2020.

[14] P. Geng, X. Y. Guo, Q. Wang et al., "Local full-size test of shield tunnel longitudinal joints," Journal of Civil Engineering, vol. 53, pp. 92-128, 2020.

[15] X. Liu, C. G. Zhang, and C. Zhang, "Investigation on the ultimate bearing capacity of longitudinal joints in segmental tunnel lining," Journal of Civil Engineering, vol. 49, p. 110, 2016.

[16] Y. L. Jin, W. Q. Ding, and H. Jiang, “Test on ultimate bearing capacity of segment joint in shield tunnel with large rectangular cross-section," China Journal of Highway and Transport, vol. 30, pp. 143-148+155, 2017.

[17] K. Feng, C. He, and M. Q. Xiao, "Bending tests of segment joint with complex interface for shield tunnel under high axial pressure," Journal of Civil Engineering, vol. 49, p. 99, 2016.

[18] C. J. Gong and W. Q. Ding, "Experimental investigation on ultimate bearing capacity of steel fiber reinforced concrete segment joints in shield tunnels," Journal of Highway and Transport, vol. 30, p. 134, 2017.

[19] K. Nishikawa, "Development of a prestressed and precast concrete segmental lining," Tunnelling and Underground Space Technology, vol. 18, no. 2-3, p. 243, 2003.

[20] H. M. Zhang, D. M. Fu, and C. Guo, Study on Load Test of Segment Joint in Shield Tunnel, pp. 28-41, Modern Tunneling Technology, Chengdu, China, 2002.

[21] J. G. Nie, M. X. Tao, L. L. Wu et al., "Advances of research on steel-concrete composite bridges," Journal of Civil Engineering, vol. 45, pp. 110-122, 2012.

[22] J. G. Nie, M. X. Tao, Y. Huang, S. Tian, and G. Chen, "Research advances of steel-concrete composite structural systems," Journal of Building Structures, vol. 31, no. 6, pp. 71-80, 2010.

[23] K. Ma, Y. Ma, and B. Liu, "Quasistatic cyclic tests and finite element analysis of low-aspect ratio double steel concrete composite walls," Advances in Civil Engineering, vol. 2019, Article ID 5917380, 12 pages, 2019.

[24] Z. Zhou, J. Qian, and W. Huang, "Numerical study on deformation capacity of steel plate reinforced concrete shear walls," Advances in Civil Engineering, vol. 2019, Article ID 9701324, 13 pages, 2019.

[25] Z. Chen, J. Wu, J. Liu, and C. Hu, "Out-of-plane bending and shear behaviors of steel plate-concrete walls for nuclear power plants," Advances in Civil Engineering, vol. 2020, Article ID 2765193, 16 pages, 2020.

[26] Y. Yu, M. Gan, Y. Zhang, L. Li, and H. Zhang, "Experimental research on antiseismic performance of high-strength concrete high-shear walls with built-in steel plates," Advances in Civil Engineering, vol. 2019, Article ID 4769404, 22 pages, 2019.

[27] Q. Q. Liang, B. Uy, H. D. Wright, and M. A. Bradford, "Local and post-local buckling of double skin composite panels," Proceedings of the Institution of Civil Engineers-Structures and Buildings, vol. 156, no. 2, pp. 111-119, 2003.
[28] Q. Q. Liang, B. Uy, H. D. Wright, and M. A. Bradford, "Local buckling of steel plates in double skin composite panels under biaxial compression and shear," Journal of Structural Engineering, vol. 130, no. 3, pp. 443-451, 2004.

[29] S. M. Tian, "Research on design method of shear studs in steel plate-concrete shear walls," Building Structure, vol. 46, pp. 61-66+84, 2016.

[30] L. Wu, L. An, and J. Li, "Shear capacity of open sandwich steel plate-concrete composite slab: experimental and analytical studies," Advances in Civil Engineering, vol. 2019, Article ID 4726538, 14 pages, 2019.

[31] Y. Yang, J. B. Liu, J. S. Fan, and X. Nie, "Experimental study on flexural capacity of steel plate-concrete composite slabs," Journal of Building Structures, vol. 34, pp. 24-31, 2013.

[32] J. Jiang, S. P. Chiew, C. K. Lee, and P. L. Y. Tiong, "An experimental study on residual stresses of high strength steel box columns," Journal of Constructional Steel Research, vol. 130, pp. 12-21, 2017.

[33] J. Jiang, S. P. Chiew, C. K. Lee, and P. L. Y. Tiong, "A numerical study on residual stress of high strength steel box column," Journal of Constructional Steel Research, vol. 128, pp. 440-450, 2017. 